\title{
Spinal cysticercosis. Case report and review
}

\author{
A Isidro-Llorens MD, F Dachs MD, J Vidal MD, M Sarrias MD \\ The Institut Guttmann Centre de Paraplegics, Barcelona, Spain.
}

Cysticercosis is the commonest parasitic disease to affect the central nervous system (CNS). ${ }^{1-3}$ According to the World Health Organisation (1988), more than 2.5 million people worldwide are infected. ${ }^{3}$ Neurocysticercosis (NCC) is caused by the encysted larval form (porcine tapeworm) of Taenia solium (Cysticerus cellulosae). ${ }^{4}$ The ways in which the eggs of $T$ Solium penetrate the CNS are illustrated in Table I.

Involvement of the spinal cord in NCC varies between $1 \%{ }^{5}$ and $5 \% .^{4}$ The isolated medullary form is very rare, only 50 cases having been reported up to 1988. ${ }^{5}$ The appearance of a spinal cord compression syndrome (SCCS) is unusual and late, according to reported series, ${ }^{2-10}$ the largest being that of Sotelo $^{9}$ with 753 cases of NCC, including 10 causing SCCS, corresponding to $1.4 \%$; also the classic Dixon and Lipscomb series ${ }^{11}$ of 450 NCC with only one patient with SCCS.

Keywords: cysticercosis; paraparesis

\section{Case report}

A woman of 30 years, with no significant previous medical history, resident in Barcelona, developed sudden progressive paraparesis. An urgent myelogram showed arrest to the dye at T3/4 level. She had a laminectomy and subarachnoid vesicular formations were found.

Postoperative studies:- CSF: increased protein $(34 \mathrm{mg} / 100 \mathrm{ml})$ and eosinphilia; EEG: normal; Cranial CT scan: no evidence of pathological formations in the brain or in the posterior fossa; stools: negative; pathology: cysticercosis leptomeningea; titration: detection of antibodies of anticysticerco larger than 1/128 (results in Barcelona and Atlanta).

Four months after the first operation a progressive worsening of the residual motor deficit occurred. Therefore she had the following studies:

(1) Myelography (Fig 1) showed appearances compatible with leptomeningeal adhesions in 'flush'. In the lumbar region there was a postoperative pseudomeningocele. Lateral views showed a curious 'scalloping' on the dorsal wall of the lumbar vertebral bodies (Fig 2). ${ }^{4}$

(2) Cranial CT scan was normal.

(3) Spinal cord CT scan showed cystic forma-

Correspondence: Dr A Isidro-Llorens, Orthopaedic Surgery Department, Institut Guttmann, Garcilaso, 57, 08027 Barcelona, Spain.

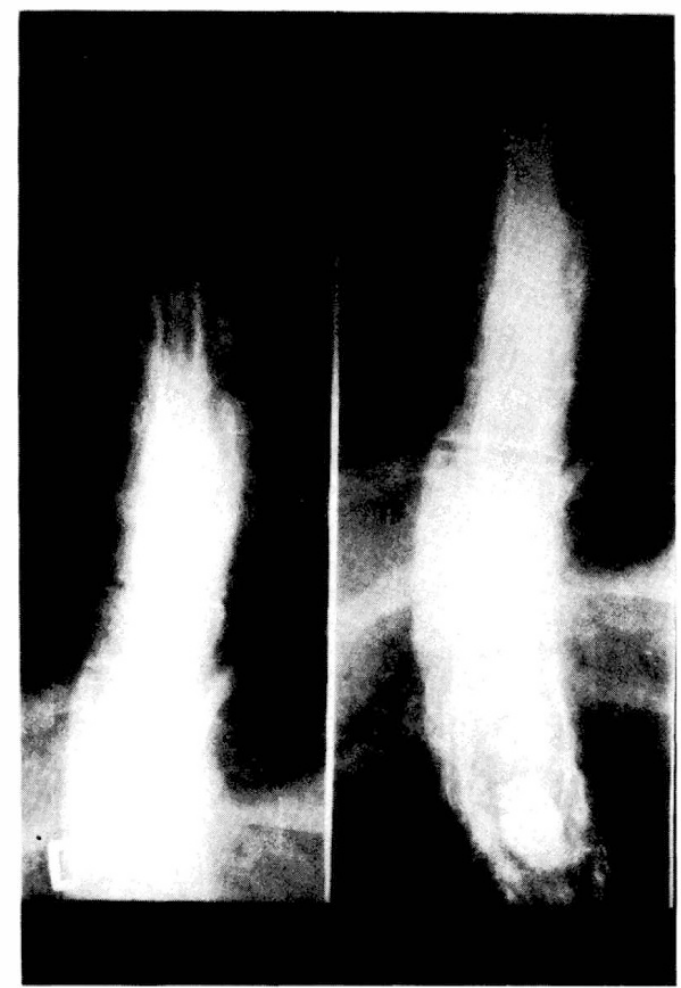

Figure 1 Myelography: AP view, after the first operation. 


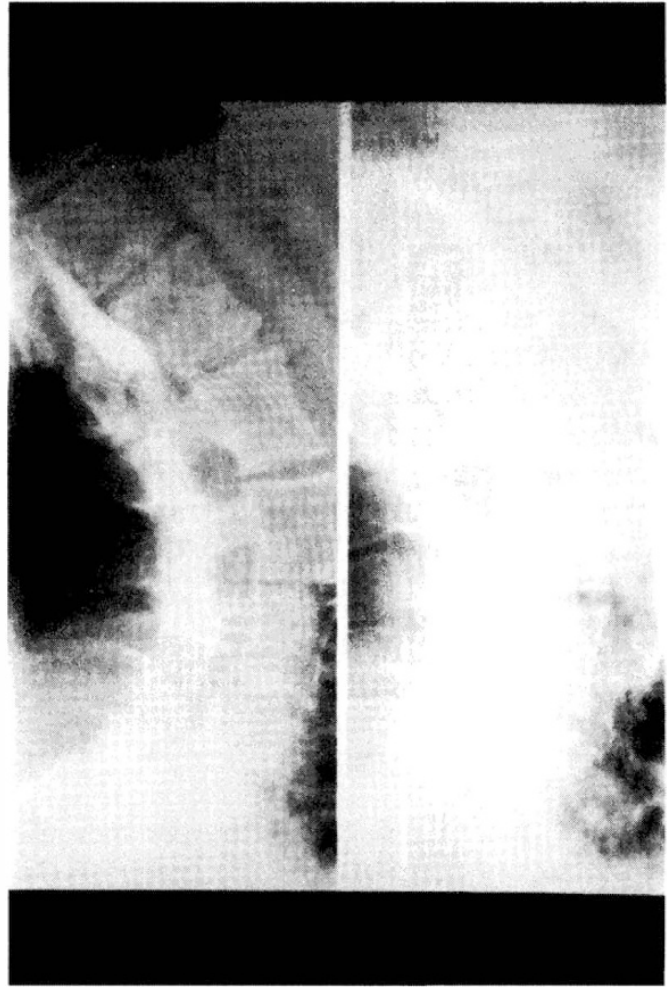

Figure 2 Myelography: lateral view after the first operation.

tions with precise limits located at the level of the laminectomy, the major component being extramedullary. The subarachnoid region showed a heterogeneous morphology caudal to the cyst, with images in the form of partitions (Fig 3).

(4) MRI showed atrophy of the cervical cord and, to a greater degree, the thoracic spinal cord, causing an anterior displacement

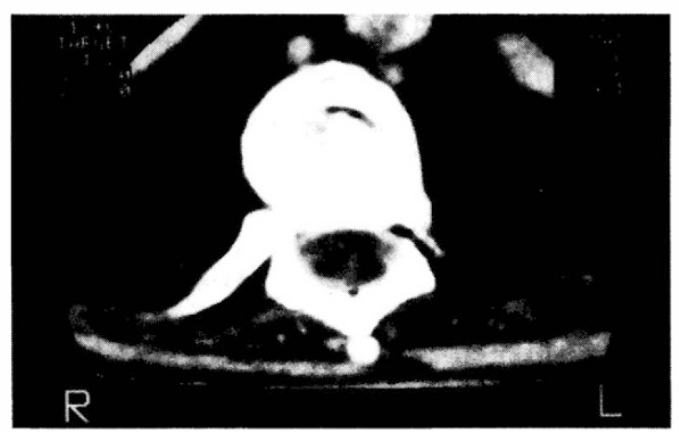

Figure 3 Thoracic CT Scan showing psuedoreticular formations inside the spinal cord. within the dural sac by a cystic collection of CSF (pseudomeningocele). The greater volume of the cystic formation was extramedullary and occupied the laminectomy area between $\mathrm{C} 7$ and L2. The thoracic spinal cord showed a number of intramedullary cystic cavities in interrupted segments some $3 \mathrm{~cm}$ in length. Syringomyelia was also present. The intramedullary cyst at level T7 was separated from the pseudomeningocele: its origin was unknown (Fig 4).

The patient underwent a further surgical operation during which more vesicles of Cysticercus were discovered. During the early postoperative period she had paraplegia, a spastic transverse spinal cord syndrome incomplete below the 7th thoracic neurological segment with loss of sphincter control. Motor power was 2-3 in the legs. The Frankel grade between the two operations changed from $\mathrm{D}$ to $\mathrm{C}$. Urodynamic examination showed a supranuclear type of bladder denervation. Treatment was started with praziquantel (PZQ) in doses of $50 \mathrm{mgkg} /$

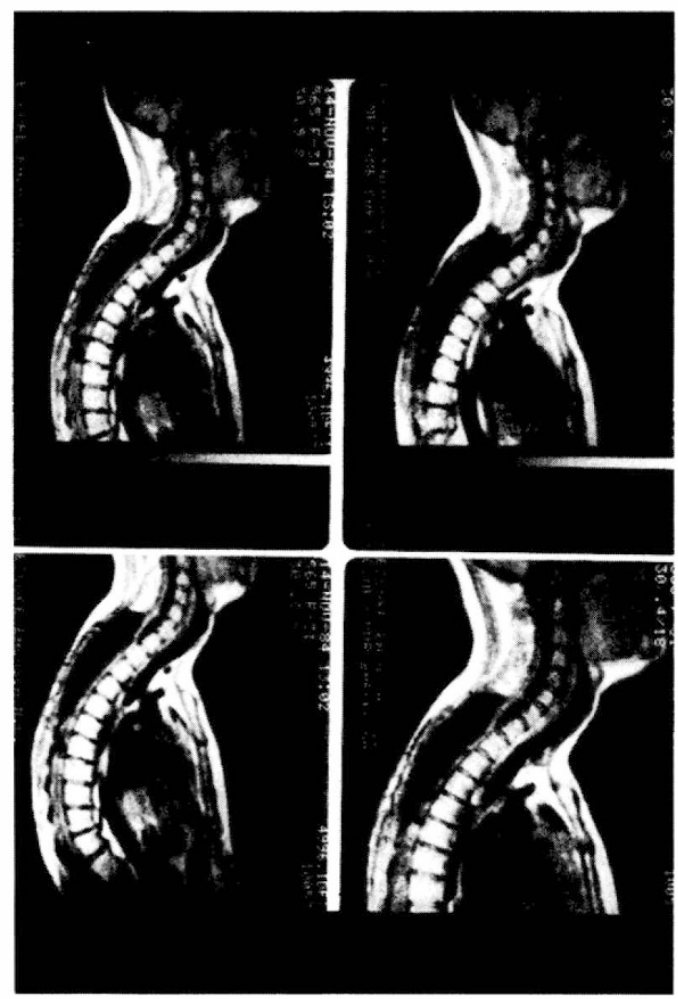

Figure 4 MRI shows a cystic formation from C7 to L2 (extramedullary) and intramedullary cystic-like cavities. 
day, along with dexamthasone $12 \mathrm{mg}$ /day for 30 days. ${ }^{8}$ The most serious secondary effects were diarrhoea and nocturnal hypotension.

\section{Discussion}

The usual way in which NCC involves the spinal cord is from an extramedullary (racemose) formation, as a result of dissemination of the vesicles through the subarachnoid space from the posterior cranial fossa (Table I). ${ }^{2,4}$

In our patient the absence of lesions in the brain (CT Scan, EEG tests) led us to believe in a possible haematogenous spread for the leptomeningeal form of NCC. This route is only described for the intramedullary form, ${ }^{2,4,12}$ the lesions being localised in the areas of greatest blood flow (Table I). ${ }^{12}$

Vertebral involvement is due to indirect mechanisms and is produced by the presence of a pulsating tumour-like lesion which erodes the posterior wall of the vertebral bodies (Fig 2). This is similar to such lesions as neurofibromas, arachnoidoceles, medullary hydatids and also to lesions occurring in some genetic disorders (achondroplasia, Hurler's syndrome, Morquio's syndrome, etc). ${ }^{4}$

The neurological consequences of spinal cord involvement in NCC are due to two different mechanisms: irritation and mass effect. The progression of the spinal cord lesion is as follows: (1) inflammation due to the presence of the parasitic toxin; ${ }^{4}(2)$ mass
Table 1 Different ways of propagation of $T$ Solium from oral to the CNS

Taenia solium eggs - digestive tract - lymphatic system - porto-caval system - cardio-pulmonary circuit - CNS

Encephalon
Subarachnoid pathway
Racemose form ${ }^{11,19}$
Spinal cord
(1) Intramedullary form
${\text { (Ventricular-ependymal tract }{ }^{15}}$
(Haematic route) $)^{11,16,19}$
(2) Extramedullary form
(Subarachnoid pathway) ${ }^{11,19}$
(Haematic route? author)

effect with a SCCS, caused by the increase in the size of vesicles; and (3) arachnoiditis fibrosa, leading to medullary vascular insufficiency. ${ }^{12}$ The rate of development of a SCCS depends on the level of the lesion or lesions, their size and location, and will be related to the diameter of the spinal canal and its relation to the diameter of the spinal canal at that level or levels. ${ }^{12}$ In our patient the main lesion was in the upper thoracic region (T3/T4), where the vertebral canal is not wide, considering the size of the spinal cord there.

\section{References}

1 Kin KS, Weinberg PE (1985) Spinal cysticerosis. Surg Neurol 24: 80-82.

2 Rocca ED et al (1956) Cisticercosis intramedular. Rev Neuro-psiquiat 8: 166-173.

3 Scharf D (1987) Neurocysticercosis. 288 cases from a California hospital. Arch Neurol 45: 777-780.

4 Trelles A (1989) Cysticercosis of the nervous system. In: Wynken \& Bruyn, editors. Handbook of Neurology. North Holland Publ Co, Amsterdam: 291-315.

5 Parker F, Iladky JP, Breton JO, Mignard C, Laporte JP, Bousquet C (1988) Cysticercose racemeuse de la queue de cheval et arachnoidite Kystique. Neurochirugie 34: 280-285.

6 Canelas H, Ricciardi-Cruz O, Escalante OA (1963) Cystericersosis of the nervous system, less frequent clinical forms. Arq Neuropsiquiat 21: 277-286.

7 Lopez-Albo N (1936) Paraplejia progresiva y eosinofilia subarachnoidea. Cisticercosis meningea dorsal. Ann Med Int V: 137-151.

8 Sharma BS, Banerjee AK, Kak VK (1987) Intramedullary spinal cysticercosis. Clin Neurol Neurosurg 82: 2111-2116.

9 Sotelo J, Guerrero V, Rubio F (1985) Neurocysticercosis. A new classification based on active and inactive forms. Arch Int Med 145: 442-445.

10 Sperlescu A, Balbo RJ, Rossitti SL (1989) Breve comentario a patogenia da cisticerose espinahal. Arch Neurol (Sao Paulo) 47(1): 105.

11 Dixon HB, Lipscomb FM (1961) Spec Rep Serv Med Res Coun (London) 299.

12 Souza-Queiroz L, Pellegrini A, Callegaro D, Lopez de Faria L (1975) Intramedullary cysticercosis. J Neurol Sci 26: $61-70$. 